\title{
An Analysis of the Adventive Component of Tree and Shrub Plants of the Southeast of Russia
}

\author{
Maxim Larionov \\ Balashov Institute of Saratov State University \\ K. Marx Street, 29 \\ Balashov, Saratov region, Russian Federation 412300 \\ E-mail: m.larionow2014@yandex.ru
}

\author{
Nikolai Larionov \\ School No 2 urban district Kotelniki \\ Novaya Street, 39 \\ Kotelniki, Moscow region, Russian Federation 140054
}

Tatiana Gromova

Saratov State University

Astrakhanskaya Street, 83

Saratov, Russian Federation 410012
Irina Siraeva

Saratov State University

Astrakhanskaya Street, 83

Saratov, Russian Federation 410012

Anna Ermolenko

Saratov State University

Astrakhanskaya Street, 83

Saratov, Russian Federation 410012

\begin{abstract}
The given paper presents the results of a longterm study of the species diversity of tree and shrub plants used in landscaping of the urbanized areas of the south-east of Russia (using the example of the Voronezh region). 97 adventive species of trees and shrubs which belong to 27 families and 63 genera are established. The data on their occurrence and distribution on the objects of planting are analyzed. The taxonomic and biomorphological compositions as well as the geographical structure are investigated. The range of environmental groups of trees and shrubs was identified. The degree of implementation and the methods of importing adventive species into the composition of the urban plantations are shown.
\end{abstract}

Keywords-woody plants; shrubs; adventive flora; biomorphological and taxonomic composition; range of environmental groups

\section{INTRODUCTION}

Bringing organisms from one geographic region to another presents a significant environmental event which bears transborder and even global scopes. The scientific society admits this process as one of the key environmental problems in different countries of the world [1] [2] [3] [4] [5] [6] [7] [8] [9] [10]. There is a necessity of research about the specific features of geographical distribution, biology and ecology of allogenic species in different countries and administrative territories. That is extremely topical from the viewpoint of fundamental science and practice. Such research is necessary, first of all, in order to work out later effective measures of preventing biological invasions, in particular, species from among adventive plants in nature's ecosystems as well as under conditions of cultural landscapes where native and alien plants are cultivated for the purpose of ensuring the resistance and ecological significance of vegetation plantations, an increase of their habitat forming, economical, recreational and esthetic value for local residents.

The development of urban ecosystems happens under the conditions of active introduction processes. Introduced species are especially popular when gardening cities [11] [12] [13] [14] [15]. In urban plantations of the south-east of Russia the bulk composition of wood exotic plants obviously prevails over the representatives of local native flora. Great attention to introduced species in practice of the gardening of cities is caused by the fact that under the conditions of the urbanized environment they, in many cases, are steadier and long-lived, grow quicker than local types. Their use ensures an essential increase in esthetic and sanitary and hygienic properties of greening landings, phytooptimization of the technogenic environment, promotes a reduction of costs of cultivation of landing material, the maintenance of urban green plantings.

The cities of the south-east of Russia including the northeast of the Voronezh region are located in a forest-steppe and a steppe zone where the mixed and broad-leaved woods are combined with steppificated meadows and meadow steppes. The climate is moderately continental. Under the conditions of natural-anthropogenic including urbanized territories of the south-east of Russia the peculiarities and regularities of adventization have not been disclosed thoroughly. The towns especially those which are far from regional centres, unfortunately, are not covered by such ecological and 
botanical researches, and therefore it is important to have a clear vision about the process of distribution of adventive plants and their behavior in phytocenoses of these urban systems. Against the background of different environmental problems of the last years, first of all, of anthropogenic and chemical and sanitary and hygienic character in cities and towns (for example, in the Saratov, Voronezh regions) the task of studying the process of forming adventive components of cultural floras including phytocenoses with woody and shrubby plants as functional cores of strong ecological frames, is now especially topical and important from scientific and theoretical positions in modern urban ecology as a whole, and in the system of urban environmental engineering and the management of artificial ecosystems in particular [4, 5, 9].

It should be noted that in many south-eastern regions and including the Voronezh region, and in particular in Novokhopyorsk, Borisoglebsk, there is a constant process of an introduction the result of which is replenishment of the flora by overseas species of plants. It is connected with an increased interest to landscape building and the collection of introduced plants having high decorative qualities. The behavior of the introduced woody plants from other physiographic zones and territories is ambiguous: some types are quite acclimatized and naturalized, took root into natural phytocenoses. Other species from the places of cultivation do not leave, but play a considerable, and sometimes the leading role in the formation of city landscapes and greening complexes. In this situation overseas species of woody plants have been received an equal basis with local types, to be considered as a part of an urban dendroflora in the identification of which we took into consideration all types of tree species under the conditions of culture and the nature.

The purpose of our research is the inventory and the analysis of the contents of adventive species of woody and shrubby plants on the territory of the south-east of Russia (using the example of towns in the Voronezh region).

\section{THE MATERIALS AND METHODS OF THE RESEARCH}

The basis of the work is made by the materials of field research received by means of a route method. The geobotanical description of the areas of research and observations, an accounting of the data on the corresponding geological and geomorphological peculiarities of the area, presence or absence of the main sources of anthropogenic transformation of landscapes were carried out, an accounting of wood and shrubby plants was carried out by a route method, their systematic position was being established. The woody and shrub plants were accounted by the route method, their systematic position was established. Accounting routes represented lines covering landscaped territories with planting of woody plants and shrubs. Within the landscaped territories we registered all the plants of the representatives of life-forms of woody plants and shrubs.

The objects of the research were the adventive woody plants and shrubs extended to the territories of the towns of the Voronezh region (Novokhopyorsk, Borisoglebsk). During seven years (from 2012 to 2018) we conducted an environmental and botanical research of those territories.

\section{THE RESUlTS OF THE RESEARCH AND THEIR DISCUSSION}

During the research on the territory of the northeast of the Voronezh region 139 species of woody plants and shrubs were registered. From them, two elements enter the city component of dendroflora - native ( $30 \%$ or 42 species) and adventive (70\% or 97 species). An example of native dendroflora is representatives of the Salicaceae family, which are widely cultivated as they have high decorative qualities and are distinguished with vitality in culture.

The adventive component of dendroflora contains 97species from 63 genera which is a part of 27 families from the divisions of Magnoliophyta and Pinophyta. The last divisiont is presented by 12 species, or $12,4 \%$ from 7 genera and 3 families. Angiospermous are represented by 85 species or $87,6 \%$ from 56 genera 10 families dominate by the number of species in "Table I".

As for species varieties the leading position is held by the Rosaceae families - 12 species, or 19\%; Caprifoliaceae - 7 species, or $11,1 \%$; Pinaceae -6 species, or $9,5 \%$.

An increase in the role of the Rosaceae family is explained by a high share of decorative plants and fruit and berry cultures in gardens, parks and personal plots and also their use in gardening of the cities. For example, Armeniaca vulgaris Larm, Cerasus vulgaris Mill, Spiraea salicifolia L., Cotoneaster lucidus Schlecht.

TABLE I. THE RANGE OF THE LEADING FAMILIES OF THE URBAN DENDROFLORA IN THE VORONEZH REGION

\begin{tabular}{|c|c|c|c|c|c|c|}
\hline \multirow[t]{2}{*}{$\mathbf{p} / \mathbf{o}$} & \multirow[t]{2}{*}{ Family } & \multirow{2}{*}{$\begin{array}{l}\text { The place } \\
\text { in a range }\end{array}$} & \multicolumn{2}{|c|}{ Number of species } & \multicolumn{2}{|c|}{ Number of genera } \\
\hline & & & Absolute quantity & Share in percents, \% & Absolute quantity & Share in percents, \% \\
\hline 1. & Rosaceae & 1 & 23 & 32,4 & 17 & 39,5 \\
\hline 2. & Caprifoliaceae & 2 & 8 & 11,2 & 5 & 11,6 \\
\hline 3. & Pinaceae & 3 & 7 & 9,9 & 4 & 9,3 \\
\hline 4. & Oleaceae & 4 & 7 & 9,9 & 4 & 9,3 \\
\hline 5. & Fabaceae & $5-6$ & 6 & 8,5 & 5 & 11,6 \\
\hline 6. & Salicaceae & $5-6$ & 6 & 8,5 & 2 & 4,7 \\
\hline 7. & Cupressaceae & $7-8$ & 4 & 5,6 & 2 & 4,7 \\
\hline 8. & Aceraceae & $7-8$ & 4 & 5,6 & 1 & 2,3 \\
\hline 9. & Berberidaceae & $9-10$ & 3 & 4,2 & 2 & 4,7 \\
\hline 10. & Vitaceae & $9-10$ & 3 & 4,2 & 1 & 2,3 \\
\hline & Total: & & 73 & 75 & 43 & 68 \\
\hline & In total: & & 97 & 100 & 63 & 100 \\
\hline
\end{tabular}


The range of the genera in "Table II" shows ways of the formation of adventive fraction the dendroflora of the towns. It is uniform introduction of decorative, food and other economically significant groups of plants (species, genera Picea, Berberis, Acer).
TABLE II. THE LEADING ADVENTIVE GENERA OF THE URBAN DENDROFLORA IN VORONEZH REGION

\begin{tabular}{|l|l|l|l|}
\hline \multirow{2}{*}{ p/o } & \multirow{2}{*}{ Sorts } & \multicolumn{2}{c|}{ Number of species } \\
\cline { 3 - 4 } & & $\begin{array}{c}\text { Absolute } \\
\text { quantity }\end{array}$ & $\begin{array}{c}\text { Share in } \\
\text { percents, \% }\end{array}$ \\
\hline 1. & Acer & 4 & 13,4 \\
\hline 2. & Juniperus & 3 & 10,4 \\
\hline 3. & Picea & 3 & 10,4 \\
\hline 4. & Syringa & 3 & 10,4 \\
\hline 5. & Populus & 3 & 10,4 \\
\hline 6. & Parthenocissus & 3 & 10,4 \\
\hline 7. & Cerasus & 3 & 10,4 \\
\hline 8. & Salix & 3 & 10,4 \\
\hline 9. & Lonicera & 2 & 6,9 \\
\hline 10. & Sambucus & 2 & 6,9 \\
\hline & Total: & 29 & 46 \\
\hline & In total: & 63 & 100 \\
\hline
\end{tabular}

According to I.G. Serebryakov's classification [16], a range the biomorph (life-forms) of woody plants is created by three types. The prevailing life forms are trees, they make $53 \%$ of the total number of the registered types, they are followed by shrubs (42\%) and lianas (5\%). The composition of adventive group of the dendroflora of the north-east of the region is presented by three life forms: shrubs make 35 species, or $36 \%$; woody plants - 57 species, or $59 \%$; lianas 5 species, or $5 \%$ in "Fig. 1".

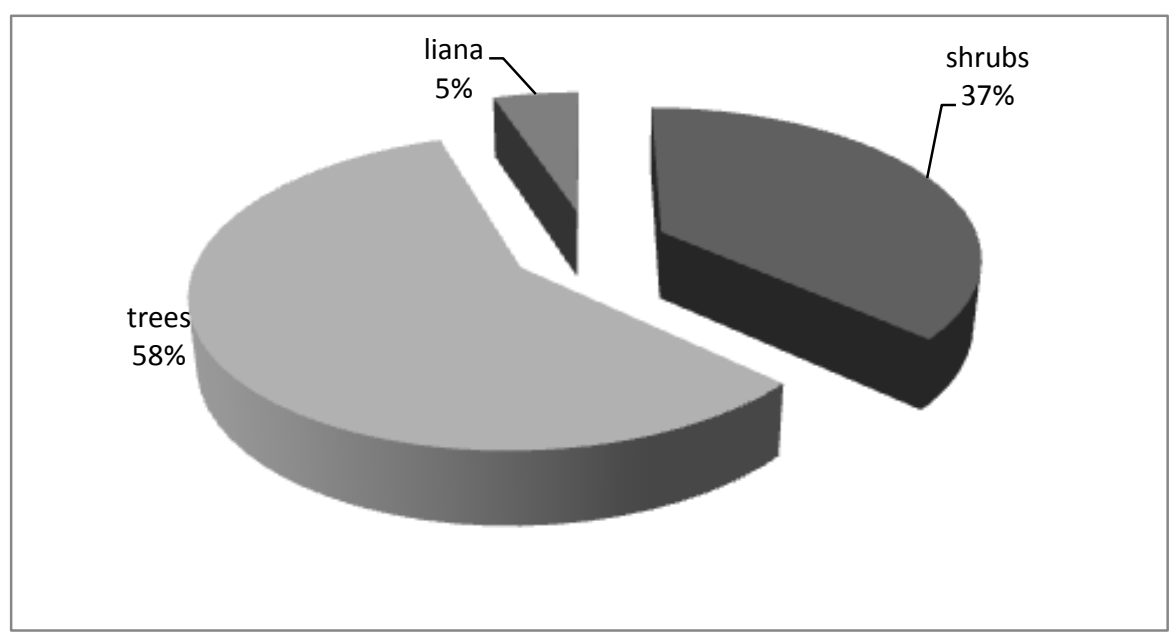

Fig. 1. A ratio of life forms of the adventive group as part of the urban dendroflora of the south-east of Russia (using the example of the Voronezh region).

In the formation of adventive fraction various geoelements and types of areas play an important role.

The North American geoelement holds the leading position and includes 32 species, or $33 \%$ (figure 2). The emergence of these species is caused by an introduction. Thuja occidentalis L, Pinus strobes L., Acer negundo L., Robinia pseudoacacia L. are representatives of the group.
The east-asian geoelement contains 17 species, or 17,6\%. These are representatives of Siberia, China, the Far East: Berberis thunbergii DC., Weigela praecox (Lemoine) Beily, Euonymus alatus Thunb, Hydrangea paniculata Sieb, Juglans mandshurica Maxim, Forsythia sieboldii.

The Central Asian geoelement takes the third place. 11 species, or 11,3\% They are: Elaeagnus angustifolia L., Juglans regia L., Armeniaca vulgaris Larm. 


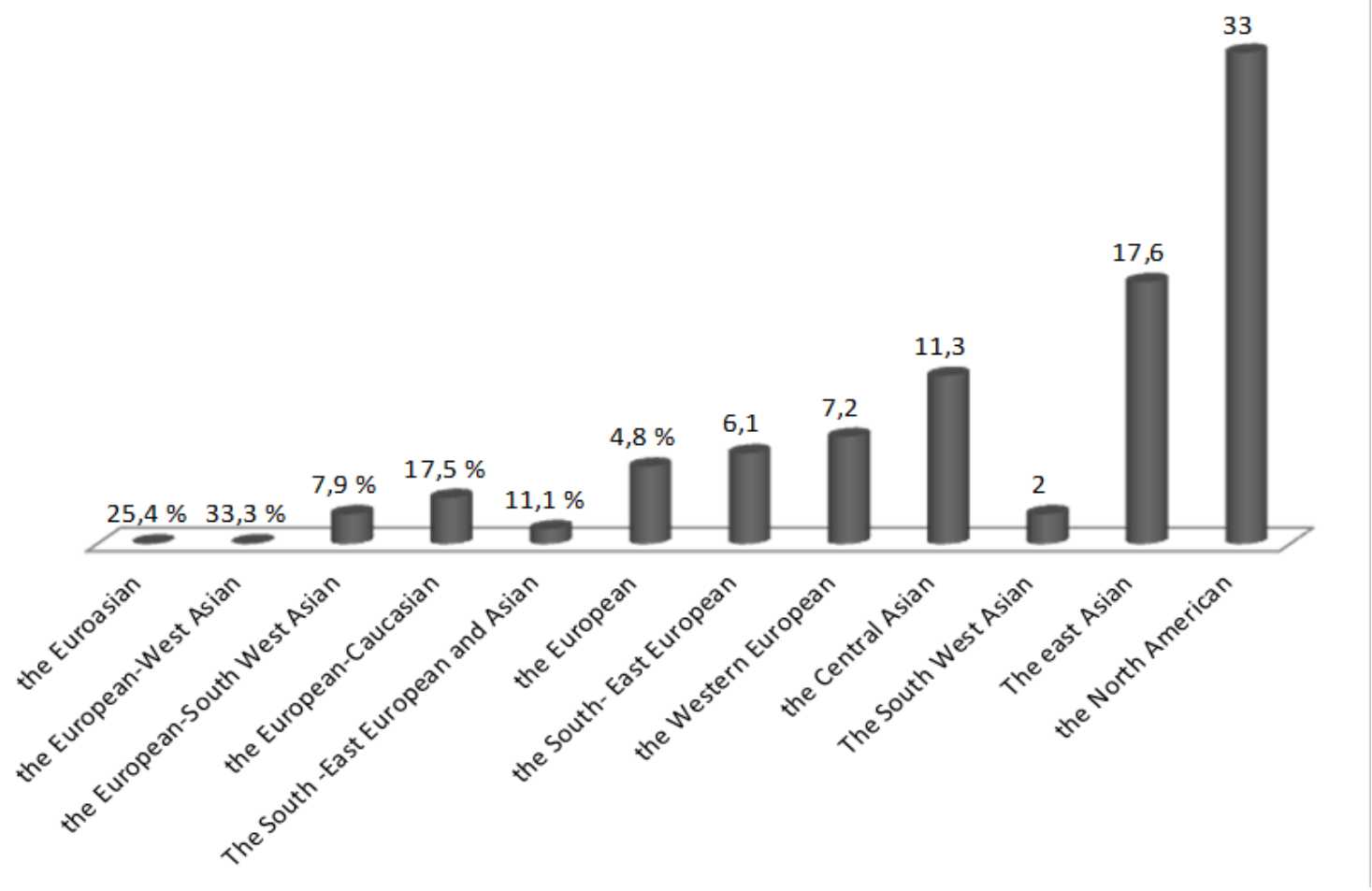

Fig. 2. A ratio of geoelements of the adventive fraction of the urban dendroflora in the Voronezh region.

Plants differently react to environmental factors: light, heat, moisture, feeding. Some prefer to live in a shadow when others develop only at good illuminating intensity. Some easily stand drought, others need excess humidification. The organisms having identical requirements to environmental conditions and reacting to particular environmental factors similarly, are united in ecological groups. For defining the resistance of species of plants to conditions of the urban environment we analysed a ratio of groups of plants according to three ecological parameters: 1) relation to humidification of the soil; 2) conditions of fertility of the soil; 3) conditions of illuminating intensity in "Table III".

In relation to humidification of the soil we distinguished 6 ecological groups. The largest of them are mesophytes $(84,5 \%)$, then by a significant margin follow gigromesophytes $(7,3 \%)$, xerophytes $(5,2 \%)$. In relation to the nutrient status of the soil mesotrophs $(87,6 \%)$ are most numerous, oligotrophic plants and eutropha divided the identical quantity $(6,2 \%$ each) In relation to conditions of illuminating intensity 2 groups were singled out in which the leading position is held by light-demanding trees and shrubs $(80,4 \%)$. Shade-enduring plants $(19,6 \%)$ are in the second place.
TABLE III. A RANGE OF ECOLOGICAL GROUPS OF THE ADVENTIVE DERDROFLORA

\begin{tabular}{|l|l|l|l|}
\hline p/o & Ecological group & \multicolumn{1}{|c|}{$\begin{array}{c}\text { Number } \\
\text { of species }\end{array}$} & $\begin{array}{c}\text { Share in } \\
\text { percents, \% }\end{array}$ \\
\hline \multicolumn{4}{|c|}{ Conditions of humidification of the soil } \\
\hline 1 & Xerophytes & 5 & 5,2 \\
\hline 2. & Mesoxerophytes & 1 & 1 \\
\hline 3. & Xeromesophytes & 2 & 2 \\
\hline 4. & Mesophytes & 82 & 84,5 \\
\hline 5. & Gigromezophytes & 7 & 7,3 \\
\hline 6. & Gigrophytes & 0 & 0 \\
\hline \multicolumn{5}{|c|}{ Nutrient status of the soil } \\
\hline 1. & Eutrophs & 6 \\
\hline 2. & Mexotrophs & 85 & 6,2 \\
\hline 3. & Oligotrophs & 6 & 87,6 \\
\hline \multicolumn{5}{|c|}{ Illuminating intensity conditions } \\
\hline 1. & Light-demanding & 78 & 6,2 \\
\hline 2. & Shade-enduring & 19 & 19,4 \\
\hline 3. & Shade-loving & 0 \\
\hline
\end{tabular}

As for the degree of introduction and a way of entering adventive types are subdivided into the following groups in "Table IV".

The leading position as part of adventive flora is held by xenophytes-ergaziolipophytes-kolonophytes (48 species or $49 \%$ ). These types have got to the territory of these towns as a result of an introduction. Many woody and shrubby plants which are used in gardening belong to this group and they have got accustomed well to streets of the towns. For example, Juniperus communis L., Thuja occidentalis L., Picea pungens Engelm., Larix sibirica Ledeb., Acer sacharinum L., Aesculus hippocastanum L., Sorbaria sorbifolia (L.) A. Braun. 
The second group of the advents by the number of species contains: xenophytes-ergaziofigophytes-epekophytes (13\%) Berberis thunbergii, Lonicera caprifolium L, Hyppophae rhamnoides L, the so-called "fugitives from the culture" appearing out of the places of the planting.
The third place is taken by kenophytesergaziolipophytes-epekophytes (12\%) Euonymus alatus Thunb., Cercis canadensis L., Caragana arborescens Lam.

TABLE IV. THE ADVENTIVE COMPONENT OF THE DENDROFloRA OF THE VORONEZH ReGION

\begin{tabular}{|c|c|c|c|c|c|}
\hline \multirow{2}{*}{\multicolumn{2}{|c|}{$\begin{array}{c}\text { Groups of species according to the time and way } \\
\text { of introduction }\end{array}$}} & \multicolumn{4}{|c|}{ Groups of species according to the degree of naturalization } \\
\hline & & eferophytes & kolonophytes & epekophytes & agriophytes \\
\hline \multirow{3}{*}{ archaeophytes } & xenophytes & 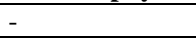 & 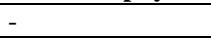 & 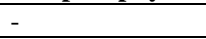 & 1 \\
\hline & ergaziolipophytes & - & - & - & - \\
\hline & ergaziofigophytes & - & - & - & - \\
\hline \multirow[t]{3}{*}{ Kenophytes } & xenophytes & 3 & 1 & - & 1 \\
\hline & ergaziolipophytes & 2 & 48 & 12 & 2 \\
\hline & ergaziofigophytes & - & 8 & 13 & 6 \\
\hline
\end{tabular}

\section{CONCLUSION}

In the south-east of Russia the formation of cultural dendroflora is continuing, including the composition of woody and shrubby plantations of urban landscapes. A great meaning on this territory has a case of adventization of flora including the town conditions of the Voronezh region as a result of an intentional introduction and unintentional, mainly, accidental introduction of woody and shrubby plants while building and arrangement of town communities and new quarters.

An increase in the process of the adventization of urban dendroflora is accompanied not only by an introduction of new species, but also by a broad resettlement of earlier appeared advents. During the research we found 139 species of trees and shrubs, among of them are 97 adventive species which are related to 64 genera and 27 families. In the formation of the adventive fraction of flora the leading position is held by the species which got to the territory of the town as a result of a intentional and unintentional introduction.

Thus, it is found that the adventive woody and shrubby plants comprise rather a high percentage $(70 \%)$ from the total number of the registered species of considered lifeforms in the composition of dendroflora and they certainly have a significant impact on its formation. That follows from the data obtained on the spectrum of the geographical elements.

The development of a management system for urban plantations of different categories in the cities and towns of the south-east of Russia is impossible without taking into account the influence of the adventive plants from among the life-form of woody and shrubby plants which represent the basis of supporting ecological frames and allow us to optimize essentially the urban environment, significantly minimizing technogenic pollutions from various sources.

\section{REFERENCES}

[1] V. V. Alekhin "Methods of study of vegetation and flora". M.: Narkompros, 1938, 208 p.
[2] Yu. K. Vinogradova, S. R. Mayorov and L. V. Khorun "Black book of flora of Central Russia: alien plant species in ecosystems of Russia”. M.: GEOS, 2010, 512 p.

[3] N. S. Kamyshev "Flora Of the Central Black Earth region and its analysis". Voronezh: VSU publishing House, 1978, 116 p.

[4] M. V. Larionov and N. V. Larionov "Ecological features of nature use in the Middle and Lower Volga region", Natural and mathematical Sciences in the modern world, 2015, No 28, pp. 58-64.

[5] M. V. Larionov and I. S. Saraeva "Systematic analysis of trees and shrubs grown in the artificial landscapes of the Voronezh region (on the example of Novokhopyorsk)" Science and education in XXI century: collection of scientific works on the materials of the International scientific-practical conference: in 5 parts. Part I. M.: AR-Konsult, 2015, pp. 28-30.

[6] S. R. Majorov, V. D. Bochkin, Yu. A. Nasimovich and A. V. Shcherbakov "Adventive flora of Moscow and Moscow region". M.: Association of scientific publications KMK, 2012, 412 p.

[7] B. M. Mirkin and L. G. Naumova "Identifikacija vegetation in the prism of the ideas of modern ecology", Biology Bulletin Reviews, 2002, vol. 63. No 6, pp. 500-508.

[8] O. V. Morozov "Participation of alien species in shaping the diversity and structure of the floras of Eastern Europe", Bulletin of the Russian Academy of Sciences: Geographical, 2003. No 3, pp. 63-71.

[9] E. N. Samoilova and M. V. Larionov "State of green plantations in the town of Balashov", Science and modernity: collection of articles of the International scientific and practical conference (Ufa, April 4, 2015), part 2. Ufa: Aerna, 2015, pp. 26-30.

[10] I. G. Serebryakov "Ecological morphology of plants. Life forms of angiosperms and conifers". M.: Higher school, 1962, 378 p.

[11] K.F. Davies, S. Harrison, H.D. Safford and J.H. Viers "Productivity alters the scale dependence of the diversity-invasibility relationship", Ecology, 2007, vol. 88, pp. 1940-1947.

[12] J. Kornas “A geografical-historical classification of synantropic plants”, Mater. Zakl. Fitosoc. Stos. VW. Warszawa-Bialowiera, 1968, vol. 25 , pp. 33-41.

[13] B. Jackowiak "Antropogeniczne przemiany flory roslin naczyniowych Poznania”, Poznan: Wyd-wo Un-tu im. A. Mickiewicza, 1990, 232 p.

[14] "Schronego Thomasa Slovnik I rozmowki rosyjsko niemieckie z XVI w. CZESC II. 1456 pod redakcja A. Falowskiego”, Einn Russich Buch, 1997: Krakow, 1997, pp. 151-159; 199-200.

[15] Schroeder F.-J. “Zur Klassifizierung der Antropochoren”, Vegetatio, 1969, Bd. 16, Fasc. 5/6, S. 225-238.

[16] I. G. Serebryakov "Ecological morphology of plants. Life forms of angiosperms and conifers”. M.: Higher school, 1962, pp. 82-84. 